\title{
Synthesis and reversible hydration behavior of the thiosulfate intercalated layered double hydroxide of $\mathrm{Zn}$ and $\mathrm{Al}$
}

\author{
S. Radha ${ }^{a}$, Wolfgang Milius ${ }^{b}$, Josef Breu ${ }^{b}$, P. Vishnu Kamath ${ }^{\text {a,* }}$ \\ a Department of Chemistry, Central College, Bangalore University, Bangalore-560 001, India \\ ${ }^{\mathrm{b}}$ Department of Inorganic Chemistry I, University of Bayreuth, Bayreuth, Germany
}

\section{A R T I C L E I N F O}

\section{Article history:}

Received 23 March 2013

Received in revised form

5 June 2013

Accepted 9 June 2013

Available online 18 June 2013

Keywords:

Layered double hydroxides

Thiosulfate ion

Hydration-dehydration

Interstratification

\begin{abstract}
A B S T R A C T
The thiosulfate-intercalated layered double hydroxide of $\mathrm{Zn}$ and $\mathrm{Al}$ undergoes reversible hydration with a variation in the relative humidity of the ambient. The hydrated and dehydrated phases, which represent the end members of the hydration cycle, both adopt the structure of the $3 R_{1}$ polytype. In the intermediate range of relative humidity values (40-60\%), the hydrated and dehydrated phases coexist. The end members of the hydration cycle adopt the structure of the same polytype, and vary only in their basal spacings. This points to the possibility that all the intermediate phases have a kinetic origin.
\end{abstract}

(c) 2013 Elsevier Inc. All rights reserved.

\section{Introduction}

The layered double hydroxide (LDH) of $\mathrm{Zn}$ and $\mathrm{Al}$ comprises a stacking of positively charged layers of the composition $\left[\mathrm{Zn}_{2} \mathrm{Al}\right.$ $\left.(\mathrm{OH})_{6}\right]^{+}$, with anions intercalated in the interlayer region. A wide variety of anions like monoatomic halides, simple inorganic anions like $\mathrm{CO}_{3}{ }^{2-}, \mathrm{SO}_{4}{ }^{2-}, \mathrm{NO}_{3}{ }^{-}, \mathrm{IO}_{3}{ }^{-}$and organic anions like sulfonates, phosphonates, and carboxylates can be lodged in the interlayer [1]. By virtue of their interlayer chemistry they find extensive applications as anion exchangers, adsorbents, catalysts, sensors, drug delivery agents, and fire retardants [2-4].

The structure of the $\mathrm{LDH}$ is modeled on that of the mineral brucite, $\mathrm{Mg}(\mathrm{OH})_{2} \cdot \mathrm{Mg}(\mathrm{OH})_{2}$ comprises a hexagonal close packing of hydroxyl ions in which alternative layers of octahedral sites are occupied by $\mathrm{Mg}^{2+}$ ions. This arrangement of atoms leads to a stacking of charge-neutral metal hydroxide layers having the composition $\left[\mathrm{M}^{\mathrm{II}}(\mathrm{OH})_{2}\right]$. When a fraction, $x$, of the divalent metal is substituted with a trivalent metal such as $\mathrm{Al}^{3+}$, the layers acquire a positive charge with a composition $\left[\mathrm{M}_{1-x}^{\mathrm{II}} \mathrm{Al}{ }_{x}(\mathrm{OH})_{2}\right]^{x+}$. Anions along with the water molecules enter the interlayer for charge compensation.

Thiosulfate $\left(\mathrm{S}_{2} \mathrm{O}_{3}{ }^{2-}\right)$ is one of the simple inorganic anions with $C_{3 v}$ symmetry. Thiosulfate is interesting as it has $S$ in two different oxidation states and is a well-known redox reagent [5]. It forms soluble metal complexes [6] and is used for

\footnotetext{
* Corresponding author.

E-mail addresses: josef.breu@uni-bayreuth.de (J. Breu), vishnukamath8@hotmail.com (P.V. Kamath).
}

dechlorination of water [7]. Owing to these properties, thiosulfate finds applications in several fields as a titration standard [8], as an agent in rapid dechlorination of water [9], antidote to cyanide poisoning [10], metal cleaning agent [11], antirheumatic [12], in silver halide photography [13], and in fabric and paper bleaching [8]. Despite its importance, there are only a few reports of thiosulfate intercalation into the LDH gallery. Thomas et al. [14,15] report the synthesis of thiosulfate-LDH by anion exchange and study the intracrystalline oxidation of thiosulfate in the interlayer using $\mathrm{H}_{2} \mathrm{O}_{2}$ and $I_{2}$ to derive sulfate-LDHs devoid of carbonate contamination. Different conditions yield different polytypes of the sulfate LDH. Khan et al. [16] report the release kinetics of intercalated thiosulfate ions from [Mg-Al] and [ $\mathrm{Li}-\mathrm{Al}] \mathrm{LDHs}$ into water and dodecylsulfate solution for its possible applications in textile industries. However, the authors in both the cases have not focussed on the structure and hydration behavior of the thiosulfate-LDH.

Thiosulfate is an oxo-anion whose structure is similar to sulfate with one of its $O$ atoms replaced by $S$. Sulfate LDHs are known to exhibit a wide variety of polytypic structures [17]. They also exhibit interesting basal spacing dynamics owing to hydrationdehydration of the interlayer [18]. Given the interesting properties of the thiosulfate ion and its close structural relationship with the sulfate ion, in this paper, we investigate the synthesis of thiosulfate intercalated $\mathrm{LDHs}$ and study their hydration behavior. We focus on polytypism among $\mathrm{S}_{2} \mathrm{O}_{3}{ }^{2-}$ - $\mathrm{LDHs}$ and the relative humidity induced basal spacing dynamics and possible interpolytype transformations. 


\section{Materials and methods}

Thiosulfate intercalated LDHs were synthesized by both coprecipitation and anion exchange.

\subsection{Co-precipitation}

In a typical coprecipitation, $50 \mathrm{~mL}$ of mixed metal nitrate solution, $\left(\left[\mathrm{Zn}^{2+}\right] /\left[\mathrm{Al}^{3+}\right]=2\right)$ was added to a reaction vessel containing a $\mathrm{Na}_{2} \mathrm{~S}_{2} \mathrm{O}_{3}$ solution $(100 \mathrm{~mL})$ having 10 times excess of the stoichiometric requirement of the thiosulfate ion. A constant $\mathrm{pH}$ was maintained during the synthesis by simultaneous addition of $\mathrm{NaOH}$ using a Metrohm model 718 STAT titrino operating in the pH STAT mode. The temperature was kept constant at $60^{\circ} \mathrm{C}$ and $\mathrm{N}_{2}$ was bubbled continuously. Preparations were done at different $\mathrm{pH}$ values of 8,9 , and 10 . Deionized and decarbonated water was used throughout the synthesis to avoid possible carbonate contamination. Half of the resulting slurry was then hydrothermally treated in mother liquor at $125{ }^{\circ} \mathrm{C}$ for $16 \mathrm{~h}$ (teflon lined autoclaves, $120 \mathrm{~mL}$ capacity, 50\% filling) and the rest aged at $60{ }^{\circ} \mathrm{C}$. The product obtained was separated by centrifugation followed by repeated washing with warm water and finally with acetone. The precipitate obtained was then dried at room temperature and stored in a desiccator.

\subsection{Anion exchange}

For anion exchange, the $\left[\mathrm{Zn}-\mathrm{Al}-\mathrm{NO}_{3}\right] \mathrm{LDH}$ precursor $(0.5 \mathrm{~g})$ was suspended in a solution containing sodium thiosulfate taken 20 times in excess of the stoichiometric requirement and stirred for a period of $40 \mathrm{~h}$ at the ambient temperature $\left(25-28{ }^{\circ} \mathrm{C}\right)$. In separate experiments, the exchange reaction was also carried out at $90{ }^{\circ} \mathrm{C}$. The solid was then separated from the supernatant by centrifugation, washed several times with decarbonated water and finally with acetone and dried in a desiccator.

\subsection{Characterization}

All samples were characterized by powder X-ray diffraction using a Bruker D8 Advance powder diffractometer (source $\mathrm{Cu} \mathrm{K \alpha}$ radiation, $\lambda=1.5418 \AA$ ). Data were collected at a continuous scan rate of $1^{\circ} 2 \theta \mathrm{min}^{-1}$.

In situ measurements of PXRD patterns at different relative humidities were carried out using a Panalytical X'pert MPD Pro $\mathrm{X}$-ray diffractometer ( $\mathrm{Cu} K \alpha$ radiation, $\lambda=1.5418 \AA$ ) equipped with an X'celerator Scientific RTMS and an Anton Paar temperature humidity chamber driven by a VTI corp. RH-200 humidity generator. Measurements were done at different relative humidity (hereafter abbreviated as $\mathrm{RH}$ ) values ranging from $5 \%$ to $98 \%$ at an interval of $10 \%$. The sample was allowed to equilibrate for a period of $1 \mathrm{~h}$ at each $\mathrm{RH}$ value before performing the XRD measurements.

Infrared spectra of the samples were recorded using a Bruker Alpha-P FTIR spectrometer (ATR mode, diamond crystal, 400$4000 \mathrm{~cm}^{-1}, 4 \mathrm{~cm}^{-1}$ resolution). TGA studies were carried out using a Mettler Toledo $851^{\mathrm{e}}$ TGA/SDTA system. The samples were dried at $100{ }^{\circ} \mathrm{C}$ for $30 \mathrm{~min}$. in the TG balance and then the temperature was ramped from $100{ }^{\circ} \mathrm{C}$ to $800{ }^{\circ} \mathrm{C}$ at a heating rate of $5{ }^{\circ} \mathrm{C} \mathrm{min}{ }^{-1}$ under $\mathrm{N}_{2}$ flow.

The $\mathrm{Zn}$ and $\mathrm{Al}$ contents were estimated by atomic absorption spectroscopy using a Varian Model AA240 atomic absorption spectrometer. The thiosulfate content was determined by ion chromatography using a Metrohm Model 861 Advanced Compact Ion Chromatograph fitted with a Metrosep SUP 5150 column. For determining the anion content, a pre-weighed amount of the LDH was dissolved in a minimum amount of $\mathrm{HCl}$. Standard solutions of sodium thiosulfate were used for calibrating the chromatograph response.

\subsection{Powder pattern simulations}

The PXRD patterns were indexed using the program PROZSKI [19]. Initial lattice parameters were provided based on the positions of the 006 and 110 reflections. Later these lattice parameters are refined to match all the observed reflections using the lattice constant program APPLEMAN built into the PROZSKI suite of programs and the figures of merit were determined. While indexing helps in identification of the unit cell, polytype identification was done by simulating the powder pattern using the code DIFFaX [20]. Within the DIFFaX formalism, a tactoid is treated as a stacking of layers of atoms and the PXRD pattern is computed in a recursive way. Model simulations were performed using a single layer extracted from published structure models of sulfate-LDHs (polytype $1 \mathrm{H}$ : CC No. 75542 , polytype $3 R_{1}$ : CC No. 91859). The interlayer atoms were included, wherein the apical $\mathrm{O}$ of the sulfate ion was replaced by $\mathrm{S}$, thereby assuming the orientation of the $\mathrm{S}_{2} \mathrm{O}_{3}{ }^{2-}$ ion in the interlayer to be the same as that of the $\mathrm{SO}_{4}{ }^{2-}$. Patterns corresponding to different polytypes were generated by stacking the layers with corresponding stacking vectors.

\section{Results and discussion}

$\left[\mathrm{Zn}-\mathrm{Al}-\mathrm{S}_{2} \mathrm{O}_{3}\right] \mathrm{LDHs}$ were prepared at three different $\mathrm{pH}$ values of 8,9 , and 10 . All the samples were further subjected to hydrothermal treatment to see if there is any improvement in the crystallinity. While the samples prepared at $\mathrm{pH} 8$ and 9 were highly disordered and showed no improvement on hydrothermal treatment, the sample obtained at $\mathrm{pH} 10$ showed a great improvement on hydrothermal treatment (Fig. 1). While even at pH 10, the pristine sample aged at $60{ }^{\circ} \mathrm{C}$ is still turbostratically disordered with a basal spacing of $8.7 \AA$, upon hydrothermal treatment, crystal growth as well as ordering is observed. The signal to noise ratio in the PXRD pattern is enhanced and reflections corresponding to different $h k \ell$ planes have emerged. We label this phase as $\left[\mathrm{S}_{2} \mathrm{O}_{3}-10-\mathrm{HT}\right]$. This phase could be indexed to a crystal of rhombohedral symmetry $(a=3.07 \AA, c=26.18 \AA$; FOM=23) (Table 1$)$. The observation of strong $0 k \ell$ reflections indicates that the structure corresponds to that of the $3 R_{1}$ polytype. DIFFaX simulation of the profile of the $3 R_{1}$ polytype is compared with the observed pattern in Fig. 1.

The sample obtained by anion exchange yields a $8.8 \AA-3 R_{1}$ phase very similar to the hydrothermally treated sample $\left[\mathrm{S}_{2} \mathrm{O}_{3}-10-\mathrm{HT}\right]$ and therefore all further characterization and in situ measurements are done using the latter.

[ $\left.\mathrm{S}_{2} \mathrm{O}_{3}-10-\mathrm{HT}\right]$ exhibits the $\nu_{\text {sym }}$ and $\nu_{\text {asym }}$ vibrations of the $\mathrm{S}_{2} \mathrm{O}_{3}{ }^{2-}$ ion at $1000 \mathrm{~cm}^{-1}$ and $1120 \mathrm{~cm}^{-1}$, respectively (Fig. 2). The S-S stretching vibration expected at $440 \mathrm{~cm}^{-1}$ overlaps with the $\mathrm{M}-\mathrm{O}$ bending vibrations of the metal hydroxide layer and thus cannot be distinguished. The peak at $1360 \mathrm{~cm}^{-1}$ indicates the presence of carbonate contamination in the sample.

TG-DTG data (Supporting Information, SI. 1) do not show well resolved sigmoidal steps as in carbonate LDHs, but a continuous mass loss with many points of inflection. The total mass loss observed from $30{ }^{\circ} \mathrm{C}$ to $800{ }^{\circ} \mathrm{C}$ amounts to $42 \%$. The mass loss below $200{ }^{\circ} \mathrm{C}$ is attributed to the loss of adsorbed and intercalated water molecules. The total water content present in the sample was calculated using this first mass loss. Mass loss above $200{ }^{\circ} \mathrm{C}$ is attributed to dehydroxylation and loss of the interlayer anions.

SEM images (Fig. 3) show hexagonal platelets characteristic of LDHs. The in-plane dimension is up to $1 \mu \mathrm{m}$ and the thickness is 

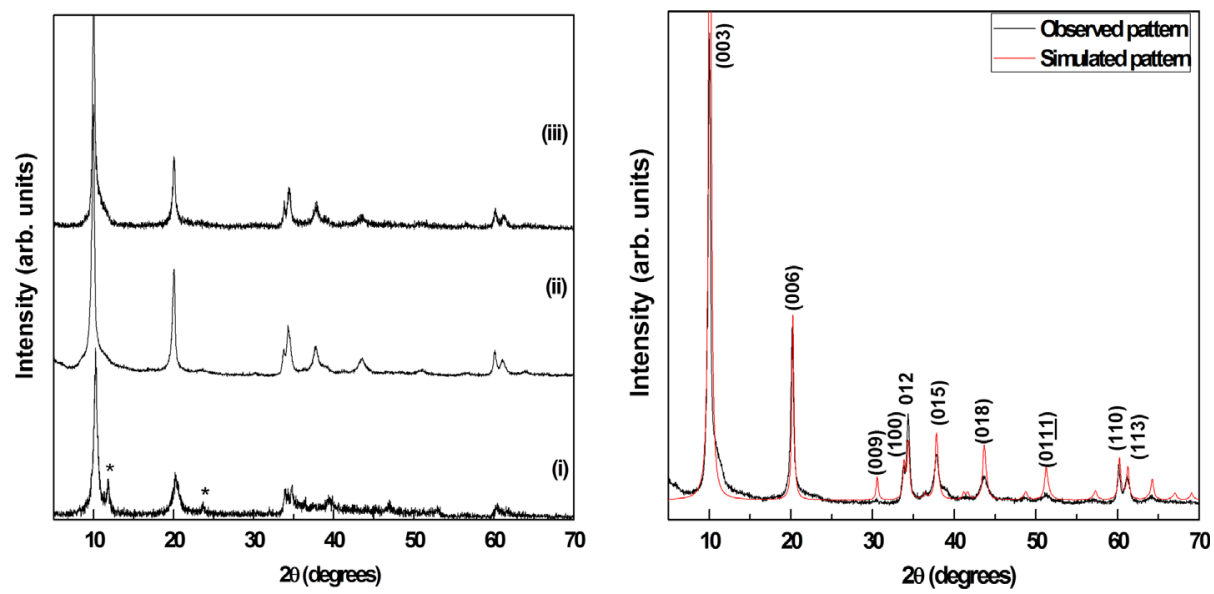

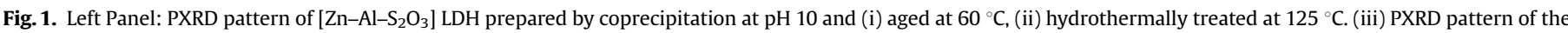

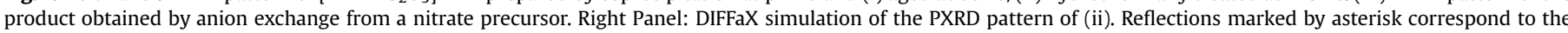
$\left[\mathrm{Zn}-\mathrm{Al}-\mathrm{CO}_{3}\right]$ impurity.

Table 1

Observed $2 \theta$ values of [ $\left.\mathrm{Zn}-\mathrm{Al}-\mathrm{S}_{2} \mathrm{O}_{3}-10-\mathrm{HT}\right] \mathrm{LDH}$ at different relative humidities with the corresponding indices obtained using PROSZKI.

\begin{tabular}{|c|c|c|c|c|c|c|c|}
\hline Ambient & & $70 \% \mathrm{RH}$ & & $100 \% \mathrm{RH}$ & & $30 \% \mathrm{RH}$ re & \\
\hline $\begin{array}{l}a=3.07 \AA \\
c=26.18 \AA \\
\mathrm{FM}=23.38\end{array}$ & & $\begin{array}{l}a=3.08 \AA \\
c=10.67 \AA \\
\mathrm{FM}=13.6\end{array}$ & & $\begin{array}{l}a=3.08 \AA \\
c=33.07 \AA \\
\mathrm{FM}=17.8\end{array}$ & & $\begin{array}{l}a=3.08 \AA \\
c=26.2 \AA \\
\mathrm{FM}=20.0\end{array}$ & \\
\hline $2 \theta$ (obs) & $h k \ell$ & $2 \theta$ (obs) & $h k \ell$ & $2 \theta$ (obs) & $h k \ell$ & $2 \theta$ (obs) & $h k \ell$ \\
\hline 10.1 & 003 & 8.3 & 001 & 8.06 & 003 & 10.1 & 003 \\
\hline 20.3 & 006 & 16.6 & 002 & 16.1 & 006 & 20.2 & 006 \\
\hline 33.8 & 101 & 25.1 & 003 & 24.2 & 009 & 33.8 & 101 \\
\hline 34.4 & 012 & 33.6 & 100 & 33.7 & 101 & 34.4 & 012 \\
\hline 37.9 & 015 & 34.7 & 101 & 34 & 012 & 37.9 & 015 \\
\hline 43.7 & 018 & 37.9 & 102 & 36.3 & 015 & 43.8 & 018 \\
\hline 51.4 & 1011 & 42.7 & 103 & 40.2 & 018 & 51.4 & 1011 \\
\hline 60.2 & 110 & 60.1 & 110 & 45.4 & 0011 & 60.2 & 110 \\
\hline 61.3 & 113 & 60.7 & 111 & 49.4 & 1013 & 61.3 & 113 \\
\hline \multirow[t]{5}{*}{64.2} & 116 & 62.8 & 112 & 51.6 & 114 & 64.2 & 116 \\
\hline & & 65.8 & 113 & 60.1 & 110 & & \\
\hline & & & & 60.7 & 113 & & \\
\hline & & & & 62.5 & 116 & & \\
\hline & & & & 65.5 & 119 & & \\
\hline
\end{tabular}

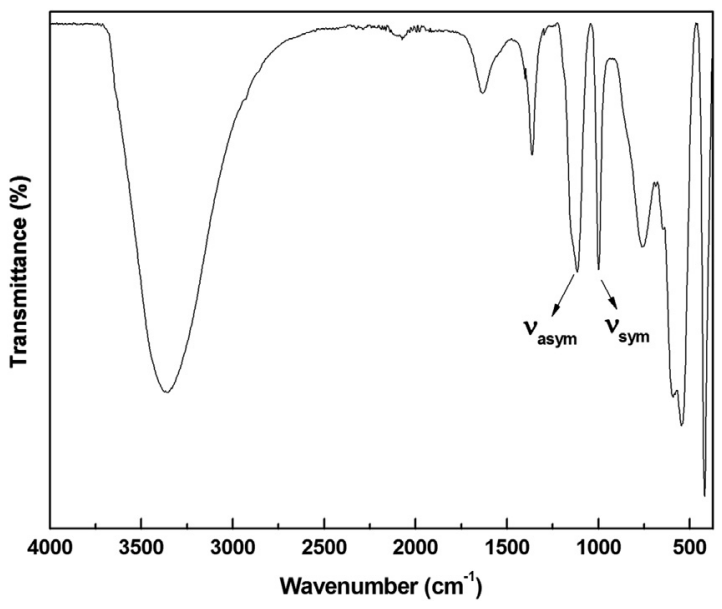

Fig. 2. IR spectrum of $\left[\mathrm{S}_{2} \mathrm{O}_{3}-10-\mathrm{HT}\right] \mathrm{LDH}$.

20-30 nm. Some of the crystallites have well faceted smooth edges indicating the cessation of crystal growth and attainment of an equilibrium aspect ratio. Others exhibit jagged edges owing to incomplete crystal growth and/or redissolution.
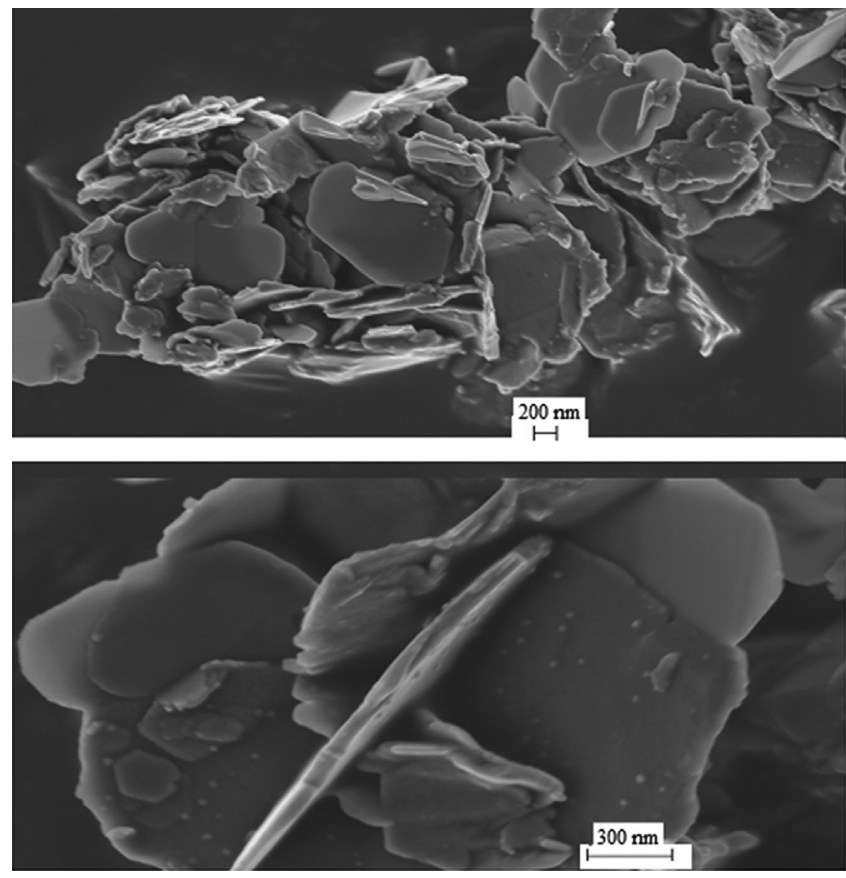

Fig. 3. SEM images of the $\left[\mathrm{S}_{2} \mathrm{O}_{3}-10-\mathrm{HT}\right] \mathrm{LDH}$.

\subsection{Relative humidity-induced variations}

Fig. 4 shows the evolution of PXRD patterns of $\left[\mathrm{S}_{2} \mathrm{O}_{3}-10-\mathrm{HT}\right]$ during the hydration cycle with increasing relative humidity. While under ambient conditions the LDH has the structure of the $8.8 \AA-3 R_{1}$ phase, on dehydration at $<5 \% \mathrm{RH}$ there is a marginal reduction in basal spacing to $8.5 \AA$.

On equilibration at $10 \% \mathrm{RH}$ the basal spacing is restored to $8.8 \AA$ A. This phase remains stable up to $50 \% \mathrm{RH}$. At $60 \% \mathrm{RH}$ a new set of basal reflections appear at $10.5 \AA\left(8.5^{\circ} 2 \theta\right), 5.3 \AA\left(16.8^{\circ} 2 \theta\right)$ and $3.5 \AA\left(25.5^{\circ} 2 \theta\right)$ in the PXRD pattern indicating the coexistence of two phases with different basal spacings. At 70\% RH only a broad hump remained at the Bragg angle corresponding to the basal spacing of the precursor phase and finally at $80 \% \mathrm{RH}$ a single phase product with a basal spacing of $10.6 \AA$ is observed. At $98 \% \mathrm{RH}$, the hydration is complete and a basal spacing of $11 \AA$ is observed. The gradual shift of the newly appearing basal reflection on going from $60 \% \mathrm{RH}$ to $98 \% \mathrm{RH}$ indicates a certain degree of random interstratification of the precursor phase in tactoids that have already 


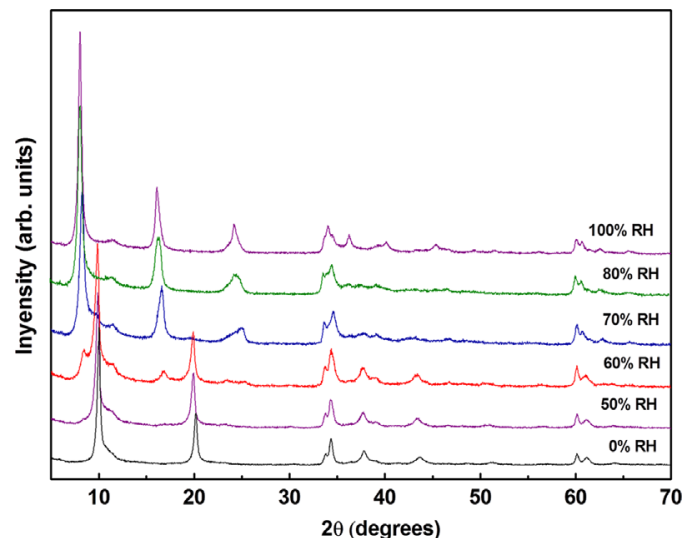

Fig. 4. Evolution of the PXRD pattern of the $\left[\mathrm{S}_{2} \mathrm{O}_{3}-10-\mathrm{HT}\right] \mathrm{LDH}$ at different relative humidities during the hydration cycle.

adopted a higher state of hydration. The vanishing degree of interstratification is mirrored by the coefficient of variation of the basal reflection series which varies as $0.57 \%$ (60\% $\mathrm{RH}), 0.86 \%$ (80\% RH), $0.65 \%(90 \% \mathrm{RH})$ and $0.27 \%(98 \% \mathrm{RH})$. In keeping with this trend, the full widths at half maximum (FWHM) of the basal reflections is most narrow at $<5 \% \mathrm{RH}$ and at $>98 \% \mathrm{RH}$, indicating of some degree of interstratification at intermediate stages [21].

Further in the range of $\mathrm{RH} 70-80 \%$ considerable disorder is observed with the extinction of $h k \ell$ peaks in the $35-55^{\circ}$ range of $2 \theta$, making polytype identification difficult. Structural order reappears at 98\% RH and DIFFaX simulation indicates the formation of a $11 \AA \AA-3 R_{1}$ polytype (Fig. 5).

To summarize, the thiosulfate-LDH expands its basal spacing from $8.8 \AA$ to $11 \AA$ during the hydration cycle. Further, two structural transformations are observed in the process

\section{$8.8 \AA-3 R_{1} \rightarrow 10.6 \AA-\mathrm{D} \rightarrow 11.0 \AA-3 R_{1}$ (D : Disordered phase)}

Since both the end members adopt the structure of the same polytype and the stacking sequence of LDH layers relative to one another is unchanged during hydration, this order-disorder-order transition is not related to stacking disorders. Rather, the disorder seen in the diffractograms is due to interstratification of phases with different basal spacings due to incomplete hydration. The disruption of periodicity along the stacking direction $\left(c^{*}\right)$, and the non-Bragg nature of the basal distance affects all $h k \ell$ reflections including those with $\ell=0$. Such an order-disorder-order transition connected with interstratified structures at intermediate stages of intercalation has previously been reported for the intercalation of Cs-hectorite [22].

Evolution of PXRD profile of the sample during the dehydration cycle (Fig. 6) shows that the fully hydrated $11 \AA \AA-3 R_{1}$ phase remains stable till $70 \% \mathrm{RH}$. At $60 \% \mathrm{RH}$ in the absence of any perceptible dehydration the profile shows a broadening of all reflections. Again this is most likely related to the onset of interstratification of the dehydrated phase in the matrix of the hydrated phase. At $40 \% \mathrm{RH}$, dehydration of the interlayer is observed resulting in a biphasic state. Complete dehydration is achieved at 30\% RH resulting in a single phase, 3-dimensionally ordered $\mathrm{LDH}$ of $3 R_{1}$ polytype and with a $8.8 \AA$ basal spacing. This phase remains stable during further dehydration to $\sim 0 \%$. The order-disorder-order transformation is reversed during dehydration.

The basal spacing changes during reversible hydration are summarized in Fig. 7. There is considerable hysteresis over one complete cycle. Clearly, as suggested by computer simulations for clays [23] hydration/dehydration of layered compounds is connected with an activation barrier and thus hysteresis. The origin of hysteresis is in the cooperative behavior of water molecules which generates an activation barrier.

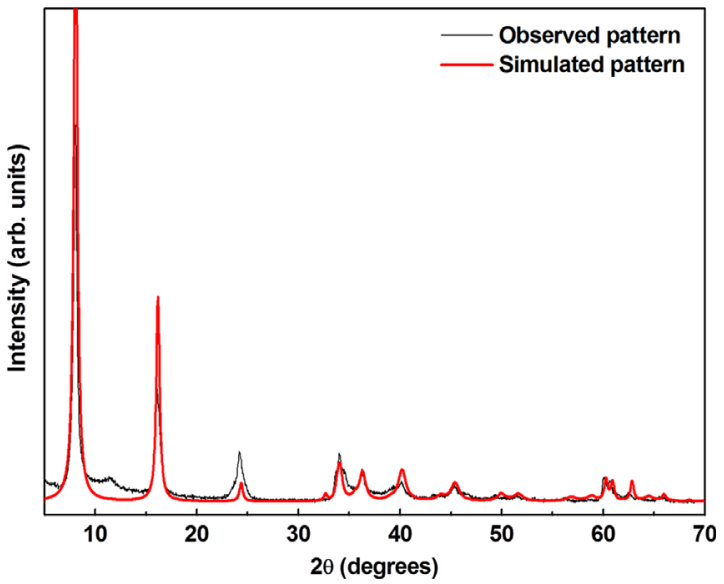

Fig. 5. PXRD pattern of $\left[\mathrm{S}_{2} \mathrm{O}_{3}-10-\mathrm{HT}\right] \mathrm{LDH}$ obtained at $>98 \% \mathrm{RH}$ overlaid with the corresponding DIFFaX simulation.

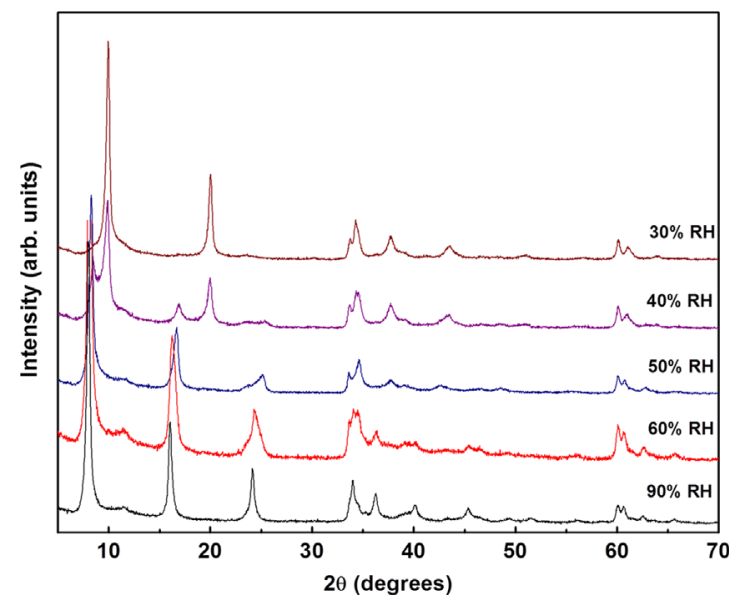

Fig. 6. Evolution of the PXRD pattern of the $\left[\mathrm{S}_{2} \mathrm{O}_{3}-10-\mathrm{HT}\right] \mathrm{LDH}$ at different relative humidities during the dehydration cycle.

We ask the question: why does the reversible hydration of the thiosulfate-LDH take place non-uniformly, leading to the coexistence of two distinct hydration states over a significant range (40-60\%) of the relative humidity?

One possibility is, the differences in the reactivity of different crystallites arise due to compositional variation between crystallites. Such variations generally occur if there is a miscibility gap between the simple hydroxides of the constituent cations $\left(\mathrm{Zn}^{2+}\right.$ and $\mathrm{Al}^{3+}$ in the present case), which leads to nucleation of crystallites with compositions on either side of the nominal value $(x=0.33$ in the present case). Such behavior, common among cationic clays, can be discounted in the present context, as the $\mathrm{LDHs}$ of $\mathrm{Zn}$ are known to crystallize with a fixed $\left[\mathrm{Zn}^{2+}\right] /\left[\mathrm{Al}^{3+}\right]=2$ $(x=0.33)$. Pauling's cation avoidance rule [24] further discounts the possibility of the stabilization of domains with $x>0.33$.

The other more likely reason for the co-existence of the end members of the hydration cycle is kinetics. The intercalation kinetics have been studied in detail for layered silicates and summarized by Breu et al. [22]. Further Weiss et al. [25] have studied the influence of particle size on the reaction mechanism of the intercalation of neutral guest molecules into kaolinite. For small crystallites in the range $0.2-0.8 \mu \mathrm{m}$ intercalation follows the so-called wedge mechanism, while larger crystals follow the ringmechanism. The LDH batch used here has a broad particle size distribution (Fig. 3) and contains particle sizes stretching over both 


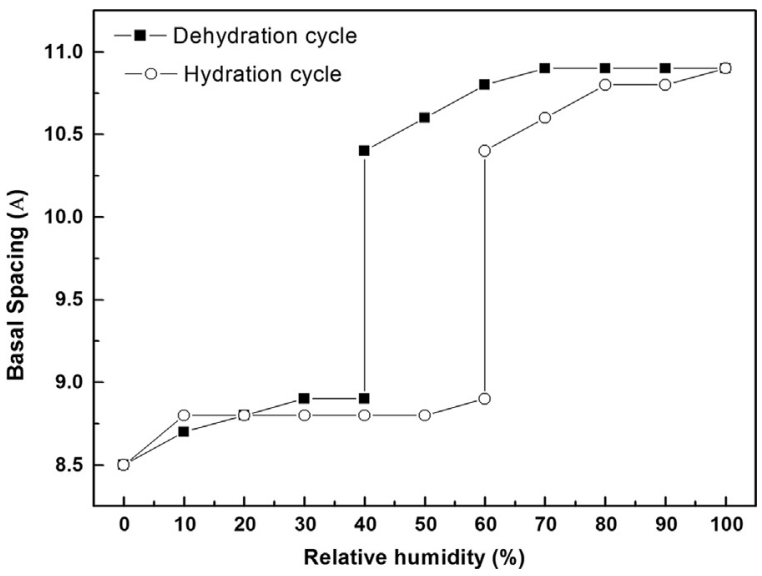

Fig. 7. Basal spacing evolution of the $\left[\mathrm{S}_{2} \mathrm{O}_{3}-10-\mathrm{HT}\right] \mathrm{LDH}$ during one complete hydration-dehydration cycle.

ranges suggested by Weiss and consequently it might be expected that for this material a mix of mechanisms result in the coexistence of crystallites with different states of hydration. von Reichenbach and Rich [26] have indeed studied cation exchange $\left(\mathrm{Ca}^{2+}\right.$ and $\mathrm{Ba}^{2+}$ for $\left.\mathrm{K}^{+}\right)$of different particle size fractions of mica and found that cation exchange of small and thin crystallites was much slower and often incomplete as compared to thicker crystallites. Apparently, the expansion of the crystallite volume increases lattice strain with a major effect on the intercalation kinetics.

The other possibility is the existence of a solution type equilibrium between the hydrated and dehydrated phases within the solid state [27]. This equilibrium can be represented as

$11 \AA-3 R_{1}(\mathrm{H}) \Leftrightarrow 8.8 \AA-3 R_{1}(\mathrm{deH})+\mathrm{H}_{2} \mathrm{O}(\mathrm{H}$ : Hydrated; deH : dehydrated $)$

As the hydrated and dehydrated LDHs are isostructural, differing only in their c-parameter, they form a homogeneous solid solution somewhat similar to and altogether more plausible than the homogeneous intergrowths of periclase (MgO) and brucite $\left(\mathrm{Mg}(\mathrm{OH})_{2}\right)$ [28]. The activity of water as reflected in the relative humidity is the driving force which shifts the equilibrium to the left during the hydration cycle and towards the right during dehydration.

\section{Conclusions}

Thiosulfate intercalated $\mathrm{Zn}-\mathrm{Al}$ LDHs were synthesized by coprecipitation and by anion exchange. The LDH undergoes reversible dehydration with the exchange of a molecule of water from the interlayer with the ambient moisture. There is considerable hysteresis accompanying this exchange as observed from the basal spacing dynamics. However the LDH adopts the structure of the $3 R_{1}$ polytype over the entire range of humidity values from $2 \%$ to $98 \%$.

\section{Acknowledgments}

Authors from India acknowledge the Department of Science and Technology (DST), Government of India (GOI) for financial support. P.V.K. is a recipient of the Ramanna Fellowship of the DST. S.R. is grateful to the Council for Scientific and Industrial Research, GOI for the award of a Senior Research Fellowship. On the German side, this work was supported by the Deutsche Forschungsgemeinschaft (SFB 840).

\section{Appendix A. Supporting information}

Supplementary data associated with this article can be found in the online version at http://dx.doi.org/10.1016/j.jssc.2013.06.010.

\section{References}

[1] D.G. Evans, R.C.T. Slade, Structural aspects of layered double hydroxides, in: X. Duan, D.G. Evans. (Eds.), Structure and Bonding: Layered Double Hydroxides, Springer, 2005.

[2] J.H. Choy, S.Y. Kwak, J.S. Park, Y.J. Jeong, J. Portier, J. Am. Chem. Soc. 121 (1999) 1399-1400.

[3] U. Costantino, V. Ambrogi, M. Nocchetti, L. Perioli, Microporous Mesoporous Mater. 107 (2008) 149-160.

[4] E. Scavetta, S. Scavetta, S. Stipa, D. Stipa, D. Tonelli, Electrochem. Commun. 9 (2007) 2838-2842.

[5] M. Nardelli, G. Fava, Acta Crystallogr 15 (1962) 477-484.

[6] S.W. Dhawale, J. Chem. Educ. 70 (1993) 12-14.

[7] H.L. Roy, Proceedings of Water Environment Federation, Disinfection 6, 2000, pp. 515-520.

[8] A.F. Holleman, E. Wiberg, in: N. Wiberg (Ed.), Inorganic Chemistry, Academic Press, Berlin-New York, 1995, pp. 554-555.

[9] C. Abbruzzese, Hydrometallurgy 39 (1995) 265-276.

[10] A.H. Hall, B.H. Rumack, J. Emerg. Med. 5 (1987) 115-121.

[11] J.T. Irwin, Conditioning of Metal Surfaces. U.S. Patent No. 2,636,009. 21 Apr 1953.

[12] H.E. Paulus, Arthritis Rheum. 33 (1990) 113-120.

[13] P. Bergthaller, Sulfur Rep. 23 (2002) 1-45.

[14] N. Thomas, Cryst. Growth Des. 12 (2012) 1378-1382.

[15] N. Thomas, M. Rajamathi, Langmuir 25 (2009) 2212-2216.

[16] A.I. Khan, A. Raghavan, B. Fong, C. Markland, M. O'Brien, T.G. Dunbar, G. R. Williams, D. O'Hare, Ind. Eng. Chem. Res. 48 (2009) 10196-10205.

[17] V.A. Drits, A.S. Bookin, Crystal Structure and X-ray Identification of Layered Double Hydroxides. In Layered Double Hydroxides: Present and Future, in: V. Rives. (Ed.), Nova Science, New York, 2001, pp. 39-92.

[18] A. de Roy, C. Forano, J.P. Besse, Layered Double Hydroxides: Synthesis and post synthesis modification. In Layered Double Hydroxides: Present and Future, in: V. Rives (Ed.), New York, Nova Science, 2001, pp. 1-39.

[19] W. Lasocha, K. Lewinski, PROSZKI, A System of Programs for Powder Diffraction Data Analysis, ver-2.4; Krakow, Poland. 1994.

[20] M.M.J. Treacy, M.W. Deem, J.M. Newsam, Computer Code DIFFaX, Version 1.807, NEC Research Institute, Inc., Princeton, New Jersey, 2000.

[21] D.M. Moore, R.C. Reynolds, Identification of Mixed-Layered Clay Minerals. In X-Ray Diffraction and the Identification and Analysis of Clay Minerals, Oxford University Press, New York261-296.

[22] J. Breu, W. Seidl, J. Senker, Z. Anorg. Allg. Chem. 630 (2004) 80-90.

[23] T.J. Tambach, P.G. Bolhuis, B. Smit, Angew. Chem. 43 (2004) 2650.

[24] L. Pauling, J. Am. Chem. Soc. 51 (1929) 1010-1026.

[25] A. Weiss, H.O. Becker, H. Orth, G. Mai, H. Lechner, K.J. Range, in: H.L. Heller (Ed.), In Proceedings of International Clay Conference, Kallai. Israel Univ. Press, Jerusalem, 1970, p. 180 .

[26] H. von Reichenbach, C.I. Rich, Clays Clay Miner. 17 (1969) 23.

[27] G.V. Manohara, P.V. Kamath, W. Milius, J. Solid State Chem. 196 (2012) 356-361.

[28] M.J. McKelvy, R. Sharma, A.V.G. Chizmeshya, R.W. Carpenter, K. Streib, Chem. Mater. 13 (2001) 921-926. 